\title{
A produção de carvão vegetal na agricultura familiar do Sul do Brasil: retrato de uma realidade escondida ${ }^{1}$
}

\section{Resumo}

Dados preliminares indicaram que a produção de carvão vegetal é uma importante fonte de renda para agricultores familiares do Sul do Brasil, embora não conste nas estatísticas oficiais. Na pesquisa de campo, envolvendo 72 famílias nos municípios de Biguaçu e Santa Rosa de Lima (SC) e Bituruna (PR), constatou-se que a atividade tem grande importância econômica e socioambiental devido à renda proporcionada e ao número de famílias envolvidas. O rendimento fornecido pela produção de carvão vegetal e a importante proporção de agricultores que o produzem, colocam a atividade em destaque pela importância econômica e social, embora permaneça ignorada pelos órgãos governamentais. As atuais restrições legais ao uso de florestas nativas vêm limitando a continuidade de sistemas tradicionais de uso do solo, sem necessariamente assegurar a melhoria ambiental destas áreas.

Palavras-chave: Carvão vegetal; Agricultura familiar; Renda; Sistemas agrícolas tradicionais.
Eliane Bauer

Mestre Agroecossistemas; bolsista Rede Sul Florestal - Brasil eliane_bauer@yahoo.com.br

Lilian de Pellegrini Elias

Mestranda Desenv. Econômico UNICAMP - Brasil

lilianpellegrini@gmail.com

\section{Luiz Augusto Araújo}

Mestre em Economia Aplicada e Pesquisador da Epagri - Brasil laraujoguto@gmail.com

\section{Luiz Toresan}

Doutor Engenharia de Produção e Pesquisador da Epagri - Brasil toresan@epagri.sc.gov.br

\section{Reney Dorow}

Mestre em Agronegócios e Pesquisador da Epagri - Brasil reney@epagri.sc.gov.br

\section{Cíntia Uller Gómez}

Doutora em Ciências Humanas e Analista da FATMA - Brasil cintiaug@gmail.com

Tássio Dresch Rech Doutor em Produção Vegetal e Pesquisador da Epagri - Brasil tassiodr@gmail.com

\footnotetext{
${ }^{1}$ Projeto de pesquisa Rede Sul Florestal, com apoio do CNPq e da FAPESC.
} 


\title{
Charcoal production in family farming in Southern Brazil: image of an hidden reality
}

\begin{abstract}
Preliminary data indicated that the charcoal production is a major source of income for family farmers in southern Brazil, although not included in official statistics. In the field research involving 72 families in the municipalities of Biguaçu and Santa Rosa de Lima (SC) and Bituruna (PR), it was found that the activity has great economic importance and environmental due to that provided income and the number of families involved. The income provided by charcoal production and the significant proportion of farmers who produce, place the activity highlighted the economic and social importance, although it remains ignored by government agencies. Current legal restrictions on the use of native forests have limited the continuation of traditional land use systems without necessarily ensuring environmental improvement of these areas.
\end{abstract}

Keywords: Charcoal; Family farming; Income; Traditional agricultural systems.

\section{Para citar este artigo:}

BAUER, Eliane; ELIAS, Lilian de Pellegrini; ARAÚJO, Luiz Augusto; TORESAN, Luiz; DOROW, Reney; ULLERGÓMEZ, Cíntia; RECH, Tássio Dresch. A produção de carvão vegetal na agricultura familiar do Sul do Brasil: retrato de uma realidade escondida. Revista PerCursos. Florianópolis, v. 16, n.30, p. 99 - 121. jan./abr. 2015.

DOI: $\mathbf{1 0 . 5 9 6 5 / 1 9 8 4 7 2 4 6 1 6 3 0 2 0 1 5 0 9 9}$

http://dx.doi.org/10.5965/1984724616302015099 


\section{Introdução}

As estatísticas oficiais muitas vezes deixam de revelar a importância que determinadas atividades econômicas possuem para os produtores rurais, por mais que sejam evidentes e estejam enraizadas nas comunidades rurais ou ainda que os seus produtos estejam sendo utilizados pela sociedade urbana. Este é o caso da produção de carvão em muitos municípios do Sul do País. Dados do Instituto Brasileiro de Geografia e Estatística (IBGE) referentes ao ano de 2011, embora mostrem a existência de produção de carvão vegetal em todas as mesorregiões do estado de Santa Catarina, indicam não existir produção de carvão na Microrregião de Florianópolis, no litoral centro norte de Santa Catarina.

Entretanto, estudo realizado em seis comunidades do município de Biguaçu, pertencente a esta microrregião, apontou a produção de carvão vegetal como fonte de renda para, pelo menos $30 \%$ das famílias que vivem da agricultura (ULLER-GÓMEZ; GARTNER, 2008). Da mesma forma, os dados do IBGE para 2011 não registram a produção de carvão vegetal nos municípios de Calmon e Matos Costa, na Mesorregião Oeste Catarinense. No entanto, o estudo realizado por Steenbock (2009) aponta que a produção de carvão, a partir do cultivo de bracatingais (formações florestais de Mimosa scabrella), contribui com cerca de 50\% da renda das famílias de algumas comunidades.

Embora poucos estudos tratem a questão de forma específica, há indícios de que a situação se repita também em outras regiões de Santa Catarina e do Sul do Brasil (RECH, 2010). As estatísticas oficiais contabilizam apenas uma fração do que é produzido, mostrando dados pouco consistentes com a realidade da produção nessas regiões, devido ao fato de que a cadeia produtiva do carvão vegetal é, na maioria das vezes, informal e não licenciada (CARRIERI, 2014).

Uma das razões para o pouco conhecimento público dessa realidade pode estar no fato de que parte da matéria-prima utilizada para a produção do carvão é oriunda da floresta nativa extraída sem autorização de corte e uso fornecida pelo órgão ambiental competente, o que faz com que a atividade, que envolve a extração da matéria prima, 
beneficiamento e comercialização, se desenvolva num ambiente de permanente clandestinidade (Ibid.).

No município de Biguaçu, especificamente, o carvão é produzido com matériaprima proveniente de florestas nativas manejadas no sistema roça de toco, também conhecido como agricultura itinerante ou de coivara. Nesse sistema, a vegetação de uma pequena área de floresta é derrubada e queimada para preparar e fertilizar a terra para o cultivo de espécies agrícolas por curto período de tempo, que se estende de um a três anos e, após a colheita, a área é deixada em pousio por longo período, que geralmente varia de 10 a 20 anos (FANTINI et al., 2010).

Nas últimas décadas, políticas de preservação centradas na restrição ao desmatamento da floresta têm tornado cada vez mais difícil esta forma de uso da terra, no qual a lenha é usada para fazer carvão, é apenas um dos produtos obtidos. Nesse sistema também são produzidos alimentos como aipim, batata-doce, feijão e outros em menor quantidade. Para que a floresta atinja o "ponto de corte para lenha", o agricultor adota a estratégia de estender o período de pousio da terra para além de 10 anos, que é o tempo de pousio máximo previsto em lei. Isso faz com que o corte raso da floresta, necessário para perpetuação do sistema denominado "roça de toco", passe a ser irregular. Nele passa a ser irregular também a produção de matéria-prima para a produção de carvão (FANTINI et al., 2010).

A roça de toco, sistema tradicional de uso da terra nos trópicos, é praticada há milhares de anos nas áreas florestadas do planeta e apresenta forte alicerce cultural e histórico nas regiões onde é praticado. Na maioria das vezes, é um componente central na propriedade e nos meios de subsistência das populações envolvidas (PADOCH; PINEDO-VASQUEZ, 2010). Atualmente, no mundo, todos os usuários do sistema vêm sofrendo os prejuízos de políticas e leis ambientais inadequadas (VAN-VLIET et al., 2012).

Pela dificuldade de obter matéria-prima legalizada, verifica-se um encadeamento de situações irregulares que se estende por toda a cadeia produtiva. Carrieri (2014) não encontrou sequer um agricultor que estivesse com todas as etapas da cadeia regularizadas, à exceção de alguns agricultores participantes de um projeto de pesquisa- 
ação em Biguaçu, SC. Essas dificuldades incluem o licenciamento ambiental do carvoejamento, a embalagem e o transporte do produto, etapas que muitas vezes não são suficientemente compreendidas por técnicos e agricultores e mesmo pelos agentes de licenciamento.

A falta de dados oficiais faz com que a existência e a importância da atividade carvoeira, bem como as dificuldades dos agricultores com a atividade, permaneçam desconhecidas, trazendo consequências negativas de ordem social, econômica e ambiental às famílias, e também aos municípios, que deixam de arrecadar com a produção.

O objetivo deste artigo é analisar a importância socioeconômica da produção de carvão vegetal para agricultores familiares de três municípios da região Sul do Brasil Biguaçu e Santa Rosa de Lima, em Santa Catarina e Bituruna, no Sul do Paraná. Especificamente, buscou-se: (1) caracterizar o perfil das famílias e dos estabelecimentos com produção de carvão vegetal; (2) descrever o sistema de produção de carvão vegetal e seus aspectos legais e socioambientais; e (3) dimensionar a participação do carvão vegetal na renda das famílias e avaliar aspectos de sua comercialização.

\section{Método}

\section{1. Áreas de estudo}

As localidades estudadas foram definidas com base em informações preliminares sobre a existência de produção de carvão vegetal, buscando abranger diferentes contextos dessa produção no Sul do Brasil.

Assim, foram escolhidos os municípios de Bituruna, no Centro Sul do Paraná, Santa Rosa de Lima, nas Encostas da Serra Geral e Biguaçu no litoral centro norte, em Santa Catarina. A localização das três áreas de estudo encontra-se na Figura 1. 


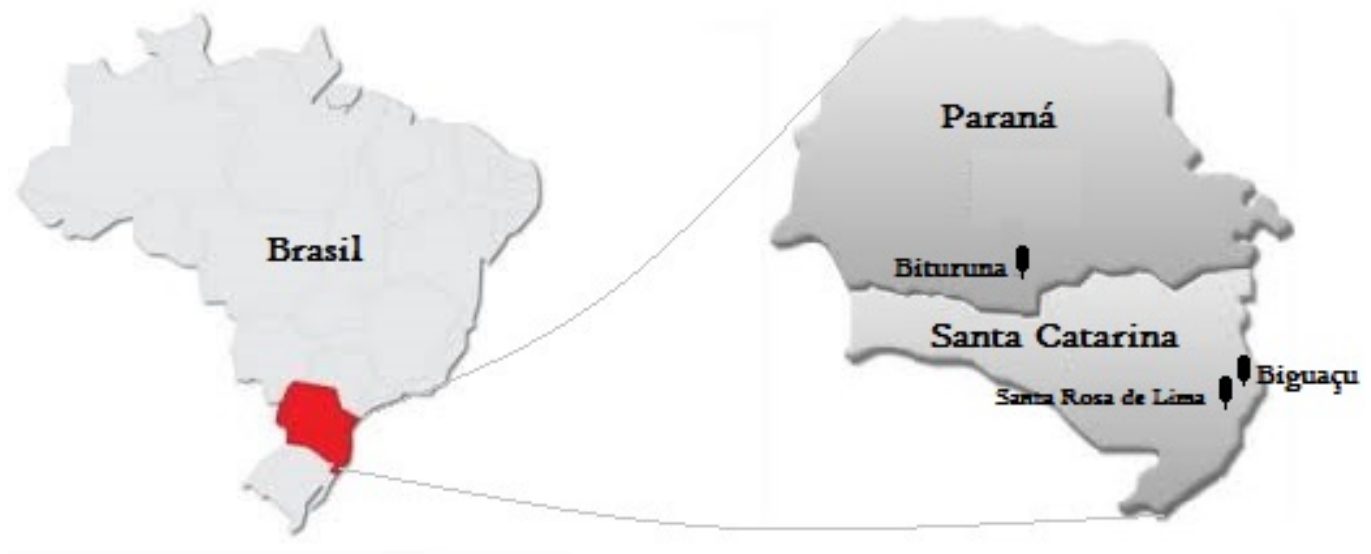

Figura 1 - Localização dos municípios de Biguaçu (SC), Santa Rosa de Lima (SC) e Bituruna (PR)

Biguaçu localiza-se na porção leste do estado de Santa Catarina, distante aproximadamente $25 \mathrm{~km}$ de Florianópolis, capital do Estado. O município possui uma população de 58.206 habitantes, formada principalmente por descendentes de portugueses vindos da Ilha dos Açores, alemães vindos de Bremen e negros vindos da África (IBGE, 2010). O estudo foi realizado em quatro comunidades rurais do município: São Mateus, São Marcos, Canudos e Fazenda de Dentro.

Santa Rosa de Lima possui uma população de apenas 2.065 habitantes e sua colonização se deu principalmente por colonos de origem alemã e italiana (IBGE, 2010). O município tem na agricultura a base da sua economia e explora o seu potencial rural que movimenta o setor agroindustrial e de serviços vinculado ao turismo rural (PREFEITURA MUNICIPAL DE SANTA ROSA DE LIMA, 2014).

O município de Bituruna possui uma população de 15.880 habitantes, composta principalmente pela etnia italiana. O município desenvolveu-se a partir da exploração de recursos naturais de valor econômico, como a erva mate e as madeiras nativas (PREFEITURA MUNICIPAL DE BITURUNA, 2014). Uma característica marcante do município é a presença de assentamentos de Reforma Agrária promovidos pelo Instituto Nacional de Colonização e Reforma Agrárias (INCRA). Segundo Carrieri (2014), existem em Bituruna sete assentamentos, com um total de 513 famílias assentadas. O estudo foi realizado no Assentamento Sonho de Rose que é o mais recente e possui 31 lotes de 
assentados. As famílias assentadas possuem um histórico de trabalho e moradia como arrendatários, empregados em sistema de faxinais, ou provêm de famílias que possuíam pouca terra para divisão entre seus herdeiros (CARRIERI, 2014).

\subsection{Procedimentos de coleta de dados}

Os dados foram obtidos pela aplicação de questionários a agricultores familiares com produção de carvão vegetal nas comunidades e nos municípios citados. Para a validação do questionário foram realizados pré-testes, e então, feitos os ajustes necessários para a versão definitiva. O questionário aplicado continha questões a respeito do agricultor e sua família, sobre a unidade produtiva, sobre as atividades agrícolas desenvolvidas e sobre a produção de carvão vegetal, aprofundando aspectos sobre mão de obra e renda obtida.

Para a identificação dos agricultores, contou-se com a colaboração de agentes locais de extensão rural e líderes comunitários. Alguns agricultores produtores de carvão pelo uso da técnica “Bola-de-Neve” (BERNARD, 1995), em que o entrevistado indica outras pessoas para a pesquisa. No município de Biguaçu, especificamente, grande parte das famílias já era conhecida pela equipe de pesquisa devido às pesquisas anteriores desenvolvidas no local desde 2008 (ULLER-GÓMEZ; GARTNER, 2008; FANTINI, 2009).

O questionário foi aplicado entre os meses de março a agosto de 2012 a agricultores de 24 estabelecimentos do município de Biguaçu (comunidades de São Mateus, São Marcos, Canudos e Fazenda de Dentro), de 23 estabelecimentos do município de Bituruna (Assentamento Sonho de Rose) e de 25 estabelecimentos do município de Santa Rosa de Lima (comunidades de Santa Bárbara, Santo Antônio, Mata Verde, Nova Esperança, Rio do Meio e Rio dos Índios). Os agricultores foram entrevistados sempre em seus estabelecimentos, sendo entrevistado o agricultor e/ou a agricultora, embora a participação de outros membros da família não tenha sido desencorajada. 
Os dados coletados se referem ao ano de 2011 e foram analisados por meio de estatística descritiva, utilizando-se do software SAS.

\section{Resultados e discussão}

Para analisar a importância econômica da produção de carvão vegetal para os agricultores familiares entrevistados apresenta-se, inicialmente, a caracterização das famílias e seus estabelecimentos, os sistemas de produção de carvão vegetal e os aspectos legais e, por último, a participação do carvão vegetal na renda e alguns aspectos da comercialização do produto.

\subsection{Caracterização das famílias e dos estabelecimentos agropecuários produtores de carvão}

As famílias são compostas, em média, por 4,3 pessoas. A Figura 2 apresenta a estrutura etária destas famílias, por município. Em Bituruna, 32,6\% dos componentes das famílias possuem menos de 14 anos e 19,5\% se encontram na faixa etária de 14 a 25 anos, o que caracteriza uma população relativamente jovem comparada aos padrões vigentes no meio rural brasileiro.

No município de Biguaçu, contrastando à situação de Bituruna, além da maior participação das pessoas com mais de 55 anos, chama atenção o baixo percentual da população jovem, com idade entre 14 e 25, possivelmente devido à evasão do grupo etário estimulado pela proximidade de centros urbanos. Desse modo, estes dados indicam existir tanto em Bituruna, quanto em Biguaçu uma grande participação de capital humano com menor capacidade produtiva, embora se situem em extremidades opostas da estrutura etária.

Em Santa Rosa de Lima a estrutura etária das famílias pesquisadas se encontra em situação intermediária à encontrada em Bituruna e Biguaçu, com predomínio das pessoas mais jovens, embora com menos importância das faixas etárias de menor idade, comparadas às famílias de Bituruna (Figura 2). 


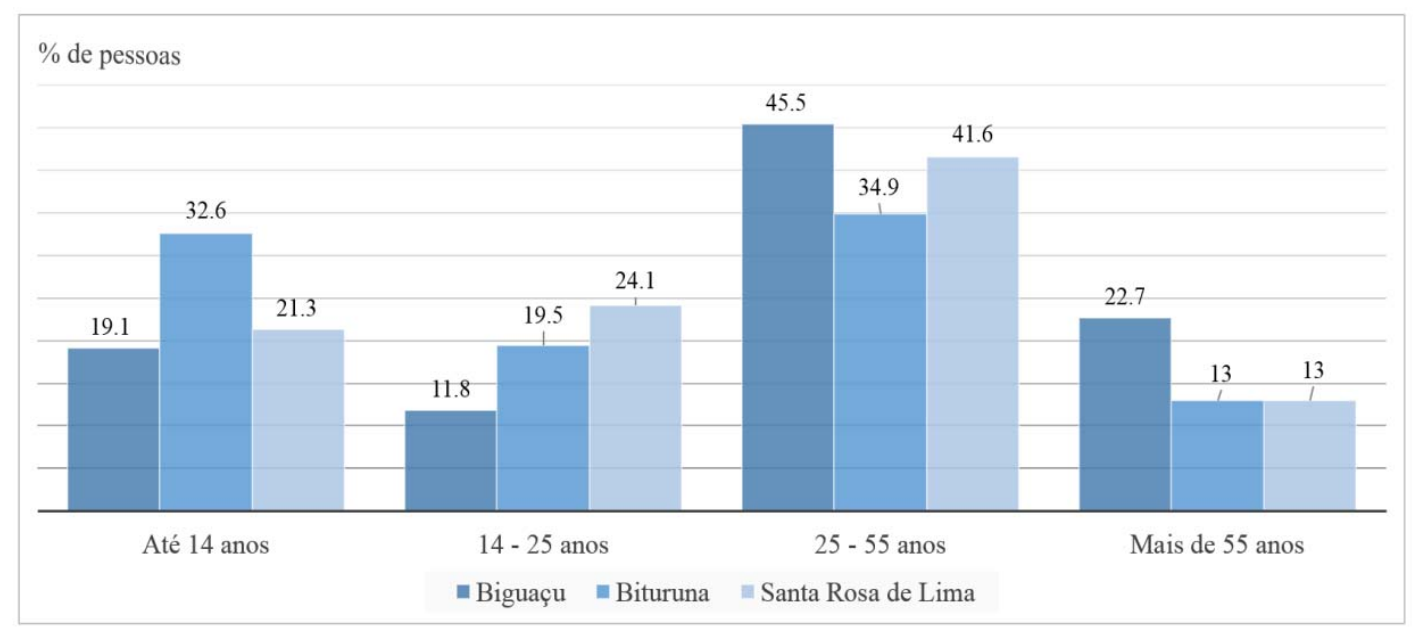

Figura 2 - Percentual dos membros das famílias pesquisadas por faixa etária Fonte: Questionários aplicados entre março e agosto de 2012.

No aspecto escolaridade, a pesquisa revela uma situação menos favorável nos municípios de Biguaçu e Bituruna, onde 73,5\% e 64,2\% das pessoas, respectivamente, não concluíram o ensino fundamental (Tabela 1).

\begin{tabular}{|l|c|c|c|}
\hline Escolaridade & $\begin{array}{c}\text { Biguaçu } \\
\%\end{array}$ & $\begin{array}{c}\text { Bituruna } \\
\%\end{array}$ & $\begin{array}{c}\text { Santa Rosa de } \\
\text { Lima } \\
\%\end{array}$ \\
\hline Não atingiu idade escolar & 3,9 & 9,8 & 6,5 \\
\hline Analfabeto & 6,7 & 3,3 & - \\
\hline Lê/escreve, mas não frequentou escola & 2,0 & 3,3 & - \\
\hline Ensino fund.I incompleto (1 ${ }^{\text {a }} 4^{\text {a }}$ série) & 60,9 & 47,8 & 40,7 \\
\hline Ensino fundamental completo $\left(5^{\text {a }}\right.$ a $8^{\text {a }}$ série) & 10,8 & 29,3 & 18,5 \\
\hline Ensino médio incompleto & 4,9 & 5,4 & 5,6 \\
\hline Ensino médio completo & 10,8 & 1,1 & 26,9 \\
\hline Ensino superior incompleto & - & - & 0,9 \\
\hline Ensino superior completo & - & - & 0,9 \\
\hline
\end{tabular}

Tabela 1 - Percentual de membros das famílias nos municípios, por nível de escolaridade Fonte: Questionários aplicados entre março e agosto de 2012.

Biguaçu também apresentou a maior participação de analfabetos entre os três municípios $(6,7 \%)$. Já em Santa Rosa de Lima não havia analfabetos entre as famílias entrevistadas, sendo também o município com maior percentual de pessoas com ensino médio completo $(26,9 \%)$. 
Quanto à situação fundiária, nos municípios de Santa Rosa de Lima e de Biguaçu a maioria das famílias são proprietárias das áreas em que trabalham, com destaque para Santa Rosa de Lima, onde $96 \%$ dos entrevistados se enquadram nessa condição (Tabela 2). Em Biguaçu, há uma participação expressiva de famílias na condição de posseiros das áreas que ocupam.

Em Bituruna, por serem áreas de assentamento, nenhum agricultor possui o título da propriedade da terra, sendo que a maioria possui o contrato de assentado. Alguns não possuem o contrato por terem assumido seus lotes através de negociação com o antigo ocupante, sendo, portanto, assentados irregulares. Outros estão morando em área cedida no lote de algum assentado. Esta última situação ocorre principalmente envolvendo familiares.

\begin{tabular}{|l|c|c|c|}
\hline & Biguaçu & Bituruna & Santa Rosa de Lima \\
\hline Área própria & 67 & 0 & 96 \\
\hline Área de posse & 29 & 0 & 4 \\
\hline Assentado & 0 & 83 & 0 \\
\hline Ocupação irregular & 0 & 13 & 0 \\
\hline Área com cessão de uso & 4 & 4 & 0 \\
\hline
\end{tabular}

Tabela 2 - Percentual de famílias por tipo de acesso à terra com a principal gleba que utilizam para trabalhar Fonte: Questionários aplicados entre março e agosto de 2012.

A área dos estabelecimentos nos três municípios não ultrapassa, em sua maioria, os 04 (quatro) módulos fiscais. Em Santa Rosa de Lima, a área média é de 38,49 ha, em Biguaçu 34,49 ha e em Bituruna 22,10 ha.

Praticamente todas as famílias pesquisadas produzem, além do carvão vegetal, alimentos para o autoconsumo ou para comercialização. No município de Biguaçu, as produções mais frequentes são de aipim, farinha de mandioca, banana, feijão, milho, batata doce, batata inglesa e hortaliças. A cana de açúcar também é produzida por muitos agricultores, sendo basicamente destinada a alimentação dos animais. Dois agricultores destinam parte da cana para a produção de melado, açúcar e cachaça.

Na produção animal em Biguaçu, existe a bovinocultura (leite e carne), a criação de galinhas e de suínos. A bovinocultura desempenha importante papel como meio de produção agrícola, já que um grande número de famílias utiliza a tração animal em suas 
atividades (principalmente no apoio à atividade carvoeira). A utilização de tração animal se faz necessária mesmo, para aqueles agricultores que têm trator ou micro-trator, porque o relevo da região é fortemente acidentado.

Em Santa Rosa de Lima, a produção agrícola é bastante diversificada, com destaque para o fumo, o milho, o feijão e diversas frutíferas, além da produção orgânica de hortaliças (brócolis, alface, repolho, couve, couve-flor, cebolinha, salsa, etc.) organizada pela Associação dos Agricultores Ecológicos das Encostas da Serra Geral (AGRECO), que possui sede neste município. O fumo ainda é um dos produtos mais importantes produzidos no município (PREFEITURA MUNICIPAL DE SANTA ROSA DE LIMA, 2014). Porém, muitas estufas de fumo vêm sendo desativadas, fato que está fortemente ligado a um processo de transição para outras atividades, principalmente à produção orgânica de hortaliças e à bovinocultura de leite, atividades que vem ganhando destaque no município nos últimos anos.

O município de Bituruna desenvolveu-se principalmente a partir da exploração de madeira e erva mate. As poucas empresas existentes no local estão ligadas ao mercado madeireiro e muitos moradores afirmam que o município possui poucas possibilidades de emprego. No assentamento Sonho de Rose, apenas 5\% dos indivíduos da amostra pesquisada que se encontram em idade economicamente ativa (entre 14 e 65 anos) trabalham em atividade não agrícola.

Além da produção de carvão vegetal, os entrevistados citaram como atividade econômica da família a extração da erva mate. Outros produtos como milho, feijão, melancia, morango, abóbora, mandioca, batata doce, batata salsa, cebola, pipoca, olerícolas diversas, leite, carne, ovos e mel também foram citados, com produção geralmente destinada ao autoconsumo.

O acesso das famílias à assistência técnica se mostrou bastante diferenciado entre as comunidades pesquisadas. Em Biguaçu, das 24 famílias entrevistadas, 11 (46\%) afirmaram não receber nenhum tipo de assistência técnica em suas atividades. Entre os que recebem, a grande maioria afirmou que a assistência é prestada apenas anualmente ou somente quando solicitada. 
Já em Santa Rosa de Lima e Bituruna, quase dois terços das famílias entrevistadas recebem assistência técnica. Entretanto, a prioridade da assistência tem se concentrado em produtos de alto valor comercial como produção orgânica de hortaliças, enquanto as atividades ligadas ao manejo florestal são geralmente esquecidas. Ou seja, nenhuma das famílias dos municípios estudados recebe qualquer assistência técnica para a produção de carvão.

A renda não agrícola está presente em grande parte das residências. Quarenta e quatro por cento (44\%) das famílias de Santa Rosa de Lima, 69,5\% das famílias de Bituruna e $75 \%$ das famílias de Biguaçu possuem outra fonte de renda além da atividade agrícola. Em Biguaçu e Santa Rosa de Lima, tem destaque principalmente a renda proveniente de aposentadorias, comércio, indústria e/ou serviços. Já em Bituruna, grande parte das famílias depende de políticas de inclusão social, visto que oito $(34,8 \%)$ famílias são beneficiárias do Programa Bolsa Família.

Em Biguaçu, 52,3\% dos membros das famílias exercem atividades não agrícolas, um número bastante superior aos outros dois municípios estudados. Esse fato representa exemplo do que afirma Wanderley (1997) quando diz que a pluriatividade constitui, frequentemente, um fenômeno positivo e contribui para as estratégias de reprodução social das famílias, seja no presente ou em uma perspectiva futura.

\subsection{Sistemas de produção de carvão vegetal seus aspectos legais e socioambientais}

Os dados do IBGE referentes a 2011 apontam uma produção de carvão de 5.805 toneladas em Bituruna e 1.350 toneladas em Santa Rosa de Lima, enquanto em Biguaçu a produção de carvão não foi detectada (IBGE, 2011). Porém, no levantamento de campo feito em 2012 com as 72 famílias que realizam a atividade, foi apurada, entre as famílias entrevistadas, uma produção de 612 toneladas de carvão em Biguaçu, 403 toneladas em Bituruna e 1.937 toneladas em Santa Rosa de Lima.

A produção de carvão vegetal é superior àquela estimada nas estatísticas agropecuárias divulgadas pelo IBGE (2011). Em Biguaçu e Santa Rosa de Lima, conversas 
informais com agricultores e técnicos da extensão rural dão conta de que existem entre 50 e 100 famílias produtoras de carvão nestes municípios. Em Bituruna, o levantamento foi realizado em apenas um assentamento, compondo uma amostra ainda menor.

Nos municípios de Biguaçu e Santa Rosa de Lima, a produção de carvão vegetal é realizada há longo tempo, principalmente em Biguaçu, onde 41,7\% das famílias pesquisadas estão na atividade há mais de 20 anos. Já em Bituruna, a produção de carvão é mais recente, sendo que $82,6 \%$ dos agricultores realizam a atividade há no máximo 10 anos, o que se justifica pelo fato desses estabelecimentos serem relativamente recentes, já que se trata de um assentamento de reforma agrária implantado recentemente. 0 mesmo não ocorre em Biguaçu e Santa Rosa de Lima, onde há tradição agrícola, e a atividade carvoeira vem de gerações anteriores.

Os fornos em uso pelos agricultores são de alvenaria, do tipo "rabo quente". Em Biguaçu, as famílias têm, em média, 1,5 fornos, em Bituruna 1,2 e em Santa Rosa de Lima 2 fornos, sendo a capacidade média de 8,94, 13,48 e 13,52 $\mathrm{m}^{3}$ de lenha, respectivamente. A maioria dos agricultores se enquadra na categoria que não necessita licenciamento (volume útil dos fornos < 50m3), mas necessita de cadastramento da atividade no órgão ambiental. Os agricultores dispõem de pouca informação sobre como proceder para a regularização ambiental da atividade. A falta deste tipo de informação e a dificuldade de obtenção de matéria-prima de forma regular fazem com que grande parte dos agricultores não tenha a atividade devidamente cadastrada no órgão ambienta competente (CARRIERI, 2014).

Em Biguaçu, a matéria-prima para a produção de carvão é oriunda principalmente do manejo da floresta nativa no sistema roça de toco. O sistema consiste na derrubada de uma pequena área de floresta, queima do material vegetal para facilitar a limpeza da área, retirada da lenha e plantio de culturas agrícolas destinadas ao mercado e ao consumo da família. Depois da colheita dos produtos, a terra é deixada em pousio e a floresta volta a se regenerar naturalmente (ou com o manejo das áreas pelos agricultores), por períodos de até 20 anos. 
Em Biguaçu, SC, o sistema de roça de toco tem sido historicamente dominante, assegurando os meios de subsistência de grande parte dos agricultores que vivem em áreas declivosas. Trabalhos desenvolvidos recentemente constataram que, após uma intensificação inicial do uso do solo, com diminuição do tempo de pousio e queda da fertilidade do solo, o plantio de espécies arbóreas nativas pelos próprios agricultores, permitiu a regeneração da floresta nativa nessas áreas (BAUER, 2012, LUCA, 2011). Entre as espécies plantadas, houve a introdução da bracatinga há mais de 50 anos. Esta espécie, embora nativa do Sul do Brasil, não é autóctone da região e sua introdução foi uma estratégia adaptativa adotada pelos agricultores para suprir a demanda de lenha nos engenhos de farinha e em outros usos nos estabelecimentos rurais (LUCA, 2011; ULLERGÓMEZ, et al. 2013).

A legislação ambiental atual restringe o corte raso de áreas de vegetação nativa nos estágios médio e avançado de regeneração, o que na prática impede os agricultores de realizar a roça de toco da forma tradicional. Em função disso, agricultores de Biguaçu vêm substituindo este sistema tradicional de uso da terra pelo plantio de eucalipto, em que a espécie é plantada após o cultivo das áreas que sofreram supressão de vegetação, como alternativa ao tradicional pousio pela regeneração natural da floresta.

Embora quase todos os agricultores tenham plantações de eucalipto, percebe-se que eles continuam produzindo carvão preferencialmente a partir de espécies nativas (Tabela 3). 


\begin{tabular}{|l|l|c|c|c|}
\hline \multicolumn{2}{|l|}{ Matéria prima } & $\begin{array}{c}\text { Biguaçu } \\
\%\end{array}$ & $\begin{array}{c}\text { Bituruna } \\
\%\end{array}$ & $\begin{array}{c}\text { Santa Rosa } \\
\text { de Lima } \\
\%\end{array}$ \\
\hline \multirow{2}{*}{$\begin{array}{l}\text { Nativas } \\
\text { diversas }\end{array}$} & Extraída do próprio estabelecimento & 35,8 & 4,4 & 36 \\
\cline { 2 - 5 } & Extraída de terceiros & 8,7 & - & 4 \\
\cline { 2 - 5 } & Adquirida de terceiros & - & - & 8 \\
\hline \multirow{2}{*}{ Bracatinga } & Extraída do próprio estabelecimento & 39,1 & 95,7 & - \\
\cline { 2 - 5 } & Extraída de terceiros & - & 17,4 & - \\
\hline \multirow{3}{*}{ Eucalipto } & Extraída do próprio estabelecimento & 21,7 & - & 44 \\
\cline { 2 - 5 } & Adquirida de terceiros & - & - & 28 \\
\cline { 2 - 5 } & Restos de serraria & 4,4 & - & 4 \\
\hline \multirow{2}{*}{ Pinus } & Extraída do próprio estabelecimento & - & - & 4 \\
\cline { 2 - 5 } & Adquirida de terceiros & - & - & 4 \\
\hline
\end{tabular}

Tabela 3 - Percentual de estabelecimentos por tipo de matéria prima e sua forma de obtenção Fonte: Questionários aplicados entre março e agosto de 2012.

No município de Santa Rosa de Lima, a lenha para a produção de carvão é oriunda em grande parte do manejo de espécies exóticas, mais especificamente do gênero Eucalyptus, mas também do corte raso de mata nativa para abertura de áreas para implantação de pastagens e novos reflorestamentos. Em geral, o pinus e o eucalipto são plantados com finalidade de produção de madeira. A lenha resultante do manejo destas espécies (desbaste, poda, restos de serraria) é utilizada para produção de carvão, embora alguns agricultores plantem o eucalipto também para a produção de lenha.

Em Bituruna, o carvão é produzido principalmente com lenha oriunda do cultivo de bracatingais (Tabela 3), que são formações florestais tradicionalmente cultivadas naquela região. Após o estabelecimento e desenvolvimento do bracatingal, grande parte dos agricultores maneja estas áreas apenas com corte raso e queima controlada, deixando que a bracatinga se regenere naturalmente, sem maiores intervenções. Muitos deles apontaram a falta de recursos financeiros para investimento na melhoria da fertilidade do solo (calagem e adubação) como limitação à substituição dos bracatingais por lavouras ou reflorestamento com espécies exóticas.

Em Bituruna, nenhum dos agricultores possuía o licenciamento ambiental. Em Biguaçu, apenas $17 \%$ dos agricultores declararam possuir o registro da atividade carvoeira. Em Santa Rosa de Lima este número é um pouco maior (29\%), mas alguns agricultores possuem o registro de apenas parte dos fornos existentes e em uso na propriedade. 
Os principais motivos citados pelos agricultores para a não regularização da atividade foram a falta de recursos financeiros e de esclarecimentos a respeito dos procedimentos. Em Biguaçu, a não regularização fundiária do imóvel e/ou a falta de reserva legal averbada na matrícula, também foram amplamente citados como motivos para a não regularização da atividade.

É comum entre os agricultores o entendimento de que somente é possível produzir carvão, do ponto de vista legal, usando matéria-prima florestal de origem exótica, embora são unânimes em afirmar que o carvão produzido a partir de espécies nativas, em especial bracatinga, tem qualidade superior ao de eucalipto e pinus.

A existência de dois sistemas de produção de carvão vegetal, que apresentam obtenção de matéria-prima (lenha) por meio do uso de florestas nativas (roça de toco e cultivo de bracatingais), num permanente ciclo de uso do recurso natural e consequente processo de regeneração da floresta, demonstra ser um sistema que traz benefícios à manutenção da biodiversidade. Isto porque este sistema evita a conversão definitiva do uso do solo em sistemas de produção intensivos em capital e tecnologia voltados ao monocultivo de espécies florestais exóticas ou de espécies agrícolas anuais.

A persistência desta forma de uso tradicional do solo tem prevenido ou minimizado o surgimento de consequências negativas, tais como insegurança alimentar, aumento de conflitos, dificuldades de acesso à terra e perda de identidade cultural, apontadas por Van-Vliet et al. (2012) em diferentes regiões do globo onde esse sistema desapareceu.

Além do benefício ambiental, a presença de sistemas tradicionais de uso do solo e de manejo florestal, pode contribuir com o equilíbrio social das regiões onde ocorrem, uma vez que envolvem pessoas em outras cadeias produtivas na produção de outros alimentos, oriundos dos mesmos sistemas. 


\subsection{Participação do carvão vegetal na renda e aspectos de comercialização}

A renda oriunda do carvão vegetal para algumas famílias representa quase o total da renda do estabelecimento rural, enquanto para outras é apenas uma renda complementar. A importância do carvão na composição da renda familiar se mostra diferenciada entre os municípios pesquisados. A participação das diferentes fontes na renda bruta total das famílias pesquisadas para os três municípios é exibida na Figura 3.

No município de Biguaçu, o carvão vegetal é, para boa parte das famílias, um complemento da renda. Nesse município, a produção de carvão tem importância não somente para a renda das famílias envolvidas, mas é parte de um sistema de uso da terra no qual a atividade está inserida - o sistema roça de toco - que resulta também na produção de lenha, de lavoura temporária, principalmente aipim, que por sua vez resulta na produção de farinha de mandioca.

Sua importância econômica em Biguaçu é menor devido à proximidade destas comunidades agrícolas a centros urbanos, isto possibilita que muitas pessoas residam no meio rural e mantenham empregos na cidade, o que é particularmente comum entre os jovens e as mulheres. É comum casos de mulheres de agricultores trabalharem como diaristas para complementar a renda da família.

O carvão produzido no município de Biguaçu chegava ao consumidor sob duas formas de apresentação: vendido em sacos de cimento reutilizados sem denominação de origem, ou em embalagens convencionais com marca registrada. Estudo realizado por Carrieri (2014) mostra que essas duas formas de apresentação acabam desenhando distintos caminhos e alcances no âmbito da cadeia já que, por causa dos limites impostos pela fiscalização, o carvão nas embalagens informais acaba sendo distribuído em locais próximos e não chega a estabelecimentos comerciais maiores porque não conseguem comercializar produtos irregulares.

Em Biguaçu, o carvão em embalagens informais é geralmente vendido a intermediários, que são também agricultores, normalmente produtores ou ex-produtores de carvão. Alguns agricultores vendem sua própria produção diretamente ao consumidor 
final. Já o carvão em embalagem registrada é vendido pelos produtores a microempresas da comunidade que revendem o produto no comércio varejista da região.

Em 2013, um grupo de agricultores praticantes da roça de toco conseguiu se regularizar e constituiu a Associação Valor da Roça. Desse modo, passou a vender o produto em embalagens diferenciadas que informam sobre o sistema de produção (roça de toco) e sobre a origem do produto (CARRIERI, 2014).
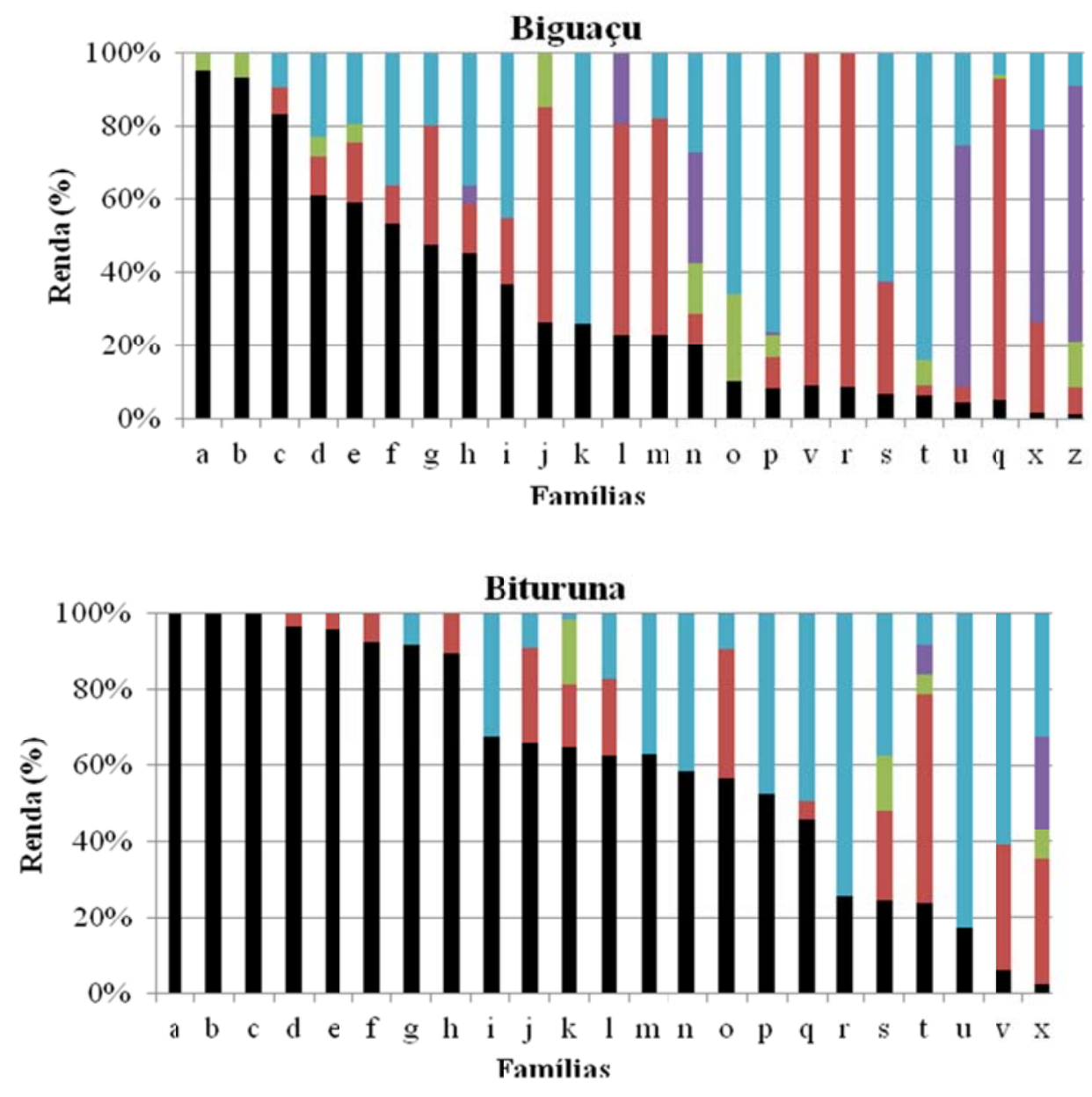


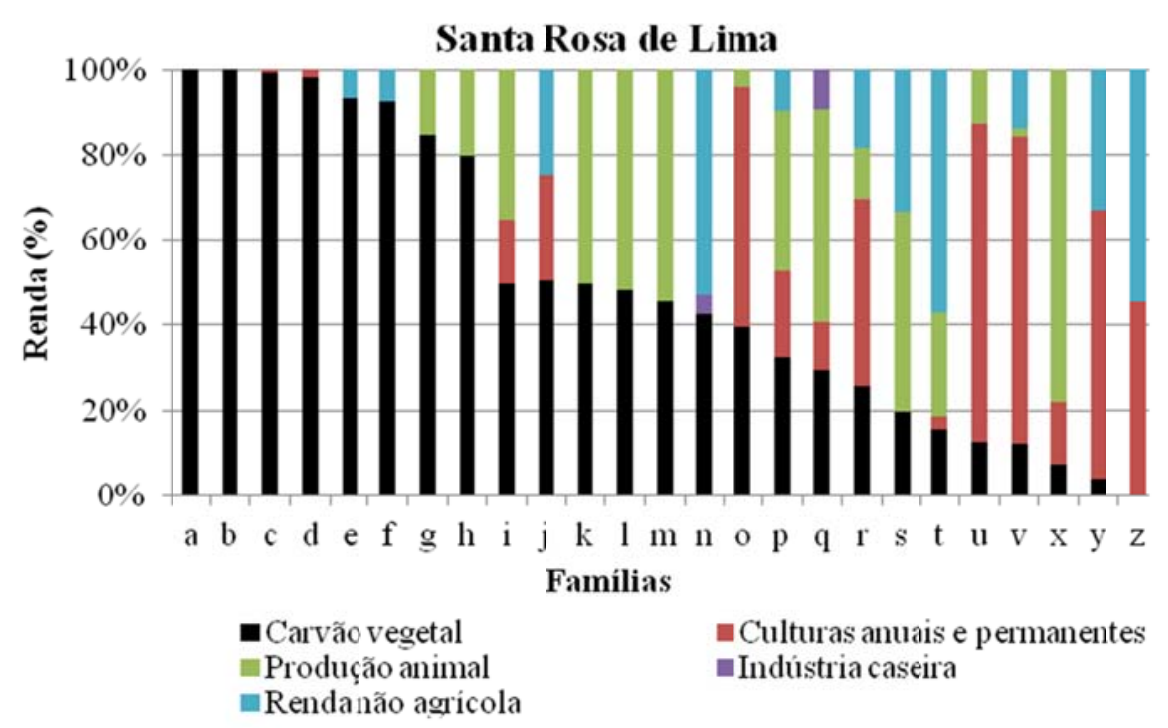

Figura 3 - Participação das diferentes fontes de renda na renda bruta total das famílias nos municípios de Biguaçu, Bituruna e Santa Rosa de Lima

Fonte: Levantamento realizado entre março e agosto de 2012.

Estas diferentes formas de comercialização influenciam diretamente no preço recebido pelo carvão. Em 2011, o valor médio recebido pelos agricultores de Biguaçu pelo carvão vendido em embalagens informais para intermediários era de R\$0,50/kg. Já a venda direta para o consumidor final nestas mesmas embalagens alcançava o valor médio de $R \$ 0,64 / \mathrm{kg}$, enquanto este valor passava para $\mathrm{R} \$ 1,25 / \mathrm{kg}$, quando em embalagens formais.

No município de Santa Rosa de Lima, para metade das famílias, a receita advinda da produção do carvão responde por mais de $50 \%$ da receita anual total, sendo que, $32 \%$ têm o carvão como receita exclusiva ou quase exclusiva (maior que $80 \%$ da receita bruta total).

A venda de carvão em embalagens informais ao consumidor, como no caso do carvão embalado no saco de cimento no município de Biguaçu, não foi constatada em Santa Rosa de Lima. Todo o carvão produzido neste município é vendido em embalagens formais, o que não significa que a cadeia do carvão esteja totalmente regularizada. De modo geral, o carvão é primeiramente vendido a um intermediário que embala o produto e, em seguida, a outro que faz a distribuição. O primeiro intermediáriio é da própria comunidade, também produtor de carvão vegetal. Já o segundo intermediário, ou 
distribuidor, é externo à comunidade e ao município. Em alguns casos, o primeiro intermediário também pode vender o carvão diretamente em estabelecimentos varejistas da região ou a consumidores finais (churrascarias) (CARRIERI, 2014).

Em Santa Rosa de Lima, o valor médio recebido pelos agricultores pelo carvão a granel vendido para intermediários era de $\mathrm{R} \$ 0,58 / \mathrm{kg}$ em 2011. Já o valor médio do carvão em embalagens formais era de $R \$ 1,00 / \mathrm{kg}$ quando vendido para intermediários e $\mathrm{R} \$ 1,10 / \mathrm{kg}$ quando comercializado no varejo ou diretamente para o consumidor final.

No município de Bituruna, o número de famílias que dependem exclusivamente ou quase exclusivamente do carvão é ainda maior, sendo que para $70 \%$ delas o carvão responde por mais de 50\% da renda bruta total. Neste local, faltam alternativas de renda para os agricultores que, por pertencerem a um assentamento recente de reforma agrária, são os mais carentes.

Naquele município, muitos agricultores trabalham apenas com produção de carvão e de erva mate, pois o solo da região precisa de insumos para implantação de lavouras. Esses insumos são caros e alguns agricultores não fazem lavoura nem mesmo para o consumo próprio. Todos os agricultores participam apenas da etapa da produção. Neste local, todo o carvão produzido é vendido a granel para intermediários externos à comunidade.

Os agricultores de Bituruna são os que recebem o menor valor pelo carvão. Os agricultores vendiam o carvão a granel para intermediários recebendo em média R\$0,36/kg. Conforme Carrieri (2014), isto se deve, provavelmente, à menor autonomia dos agricultores na comercialização do carvão deste município, em comparação com os produtores de Santa Rosa de Lima e de Biguaçu. Especialmente em Biguaçu, onde agricultores da própria comunidade, às vezes parentes ou vizinhos dos produtores, fazem o beneficiamento (envasamento) e a distribuição no mercado, numa relação pautada na confiança recíproca entre os agentes da cadeia. 


\section{Considerações finais}

O estudo realizado revelou que o carvão vegetal é uma importante atividade da agricultura familiar no Sul do Brasil, e tem destacada participação na renda da maior parte das 72 famílias entrevistadas nos três municípios estudados. O carvão vegetal representou mais da metade da renda total anual para $46 \%$ das famílias, com destaque para o município de Bituruna, onde o carvão participou com mais da metade da renda para $70 \%$ das famílias.

A renda proporcionada pela produção de carvão, associada ao número de agricultores que o produzem, coloca a atividade em destaque pela sua importância econômica, ambiental e social. A falta de informações reais sobre esta atividade da agricultura familiar tem levado à formulação de políticas ou à execução de ações inadequadas ou incompletas relacionadas ao desenvolvimento territorial dessas comunidades agrícolas, contribuindo para que os agricultores permaneçam à margem das ações oficiais de promoção do desenvolvimento.

A predominância do uso de espécies da mata nativa como matéria-prima para o carvão é um dos principais fatores que contribui para a invisibilidade e clandestinidade da atividade, uma vez que as normativas legais não levam em consideração os benefícios ambientais que os sistemas tradicionais de uso do solo e de manejo florestal trazem ao meio ambiente e à sociedade, mediante a preservação dos saberes locais das comunidades que os praticam.

Este estudo mostra que as restrições legais para o uso e manejo da mata nativa não garantem sua preservação. Ao contrário, incentivam a substituição das áreas de mata nativa pelo plantio de espécies, que possam ser exploradas sem restrições como, por exemplo, o eucalipto e o pinus, o que pode levar a uma diminuição da qualidade ambiental local pela perda da biodiversidade.

Recomenda-se novos estudos para aprofundar a compreensão dos aspectos envolvidos na produção do carvão vegetal que utiliza florestas nativas, com vistas à avaliação de sua sustentabilidade. 


\section{Referências}

BAUER, Eliane. Mudanças no uso da terra em Biguaçu-SC: agricultores em permanente processo de adaptação, 2012, 94 f.. Dissertação (Mestrado em Agroecossistemas) Universidade Federal de Santa Catarina, Florianópolis, 2012.

CARRIERI, Marina. Cadeias produtivas do carvão vegetal na agricultura familiar no Sul do Brasil. 2014, f.00. Dissertação (Mestrado em Agroecossistemas) Universidade Federal de Santa Catarina, Florianópolis, 2014.

FANTINI, Alfredo Celso. Projeto nosso carvão. Edital MCT/CNPq/MDA/SAF/Dater n $33 / 2009$.

FANTINI, Alfredo Celso et al. Produção de carvão e de saberes na agricultura familiar de SC. Agropecuária Catarinense, v. 23, p.13-15, 2010.

INSTITUTO BBRASILEIRO DE GEOGRAFIA E ESTATÍSTICA. Censo Demográfico. Rio de Janeiro: IBGE, 2010. Disponível em: <http://www.cidades.ibge.gov.br/> Acesso em: 02 de abril de 2014.

INSTITUTO BRASILEIRO DE GEOGRAFIA E ESTATÍSTICA. Produção da Extração Vegetal e da Silvicultura. Rio de Janeiro: IBGE, 2011. Disponível em:

<http://www.ibge.gov.br/home/estatistica/economia/pevs/2011/default_pdf.shtm> Acesso em: 02 de abril de 2014.

LUCA, Fernando Vieira. "Botar a roça": Agricultura de corte e queima e manejo de bracatingais em Biguaçu, SC. 2011. 77f. Trabalho de conclusão de curso - (Graduação em Agronomia) - Universidade Federal de Santa Catarina, Centro de Ciências Agrárias, , Florianópolis.-, 2011.

PADOCH, Christine; PINEDO-VASQUEZ, Miguel. Saving Slash-and-Burn to Save Biodiversity. Biotrópica, St. Louis, v.42, p.550-552, 2010.

PREFEITURA MUNICIPAL DE BITURUNA. [Página da internet]. Disponível em: <http://www.bituruna.pr.gov.br/base.php?id=historia> Acesso em: 02 de abril de 2014.

PREFEITURA MUNICIPAL DE SANTA ROSA DE LIMA. [Página da internet]. Disponível em: <http://www.santarosadelima.sc.gov.br/home/> Acesso em: 02 de abril de 2014.

RECH, Tássio Dresch. Projeto Rede Sul Florestal: PD\&I em sistemas florestais e produção de energia na agricultura familiar no Sul do Brasil. Edital CNPq Repensa 022/2010. 
STEENBOCK, Walter. Domesticação de Bracatingais: perspectivas de inclusão social e conservação ambiental. 2009, 281f. Tese (Doutorado) - Programa de Pós-Graduação em Recursos Genéticos Vegetais, Universidade Federal de Santa Catarina, Florianópolis, 2009.

ULLER-GÓMEZ, Cíntia; DOROW, Reney; ELIAS, Lilian de Pellegrini; GARTNER, Carolina. Abordagens educativas, extensão rural e agricultura familiar em Biguaçu-SC. INTERthesis (Florianópolis), v. 10, p. 287-321, 2013.

ULLER-GÓMEZ, Cíntia; GARTNER, Carolina. Um caminho para conhecer e transformar nossa comunidade. Relatório final de pesquisa vinculada ao TOR 23/2006 EPAGRI/MB2. Florianópolis, 2008. 111p.

VAN-VLIET, Nathalie; MERTZ, Ole; HEINIMANN, Andreas; LANGANKE, Tobias; PASCUAL, Unai; SCHMOOK, Birgit; ADAMS, Cristina; ; SCHMIDT-VOGT, Dietrich; MESSERLI, Peter; LEISZ, Stephen; CASTELLA, Jean-Christophe; JØRGENSEN, Lars; BIRCH-THOMSEN, Torben; HETT, Cornelia; BECH-BRUUN, Thilde; ICKOWITZ ,Amy; VU, Kim Chi; YASUYUKI, Kono; FOX, Jefferson; PADOCH, Christine; DRESSLER, Wolfram; ZIEGLER, Alan D. Trends, drivers and impacts of changes in swidden cultivation in tropical forest agriculture frontiers: a global assessment. Global Environmental Change-Human and Policy Dimensions, Oxford, v.22, n.418-429, 2012.

WANDERLEY, Maria Nazareth Baudel. O Lugar dos Rurais: o meio rural no Brasil moderno. Natal (RN). In: CONGRESSO BRASILEIRO DE ECONOMIA E SOCIOLOGIA RURAL, XXXV, Natal, 1997. Resumo dos Anais. Natal: SOBER, 1997. 